\title{
Nazal fungiform papillom
}

\author{
Nasal fungiform papilloma
}

\author{
Efser Başaran, ${ }^{1}$ Ali Ahmet Şirin, ${ }^{2}$ Hakan Kaya, ${ }^{2}$ Ali Muhammedoğlu, ${ }^{3}$ Fatma Tülin Kayhan ${ }^{2}$ \\ ${ }^{1}$ Karabük Üniversitesi, Karabük Eğitim ve Araştırma Hastanesi, Kulak Burun Boğaz Hastalıkları Kliniği, Karabük, Türkiye \\ ${ }^{2}$ Bakırköy Dr. Sadi Konuk Eğitim ve Araştırma Hastanesi, Kulak Burun Boğaz Hastalıkları Kliniği, İstanbul, Türkiye \\ ${ }^{3}$ Bakırköy Dr. Sadi Konuk Ĕ̆itim ve Araştırma Hastanesi, Patoloji Kliniği, İstanbul, Türkiye
}

\begin{abstract}
Schneiderian papillomlar (SP), burun boşluğu ve paranazal sinüsleri çevreleyen Schneiderian mukozadan köken alan, nadir görülen benign ekzofitik neoplastik proliferasyonlardır. Histomorfolojik olarak inverted, fungiform ve onkositik SP olmak üzere üç gruba ayrılırlar. İnverted ve onkositik Schneiderian varyantların aksine, fungiform SP genç yaşlarda ortaya çıkar, tipik olarak nazal septumdan kaynaklanır ve malignite ile ilişkili değildir. Fungiform SP'de en iyi tedavi yöntemi, tam cerrahi eksizyondur. Altmış sekiz yaşında kadın hasta, tek taraflı burun tıkanıklığı ve ağız kuruluğu yakınmaları ile kliniğimize başvurdu. Endoskopik muayenede sol taraf burun hava pasajını tıkayan polipoid kitle saptandı. Total olarak eksize edilen kitlenin histopatolojik inceleme sonucu, SP fungiform tip olarak bildirildi. İleri yaşlarda diğer Schneiderian varyantların aksine daha nadir görülmesi nedeniyle, fungiform SP klinik ve histopatolojik özellikleri ile literatürler eşliğinde sunuldu.
\end{abstract}

Anahtar Sözcükler: Nazal kavite; neoplazi; papillom; paranazal sinüs.

Schneiderian papillomlar (SP) burun ve paranazal sinüslerde nadir görülen etyolojisi bilinmeyen benign neoplastik proliferasyonlardır. İnverted, fungiform (ekzofitik) ve onkositik (silindirik) tip olmak üzere üç farklı histolojik alt tipi vardır. ${ }^{[1,2]} \mathrm{Bu}$ alt tiplerin her birinin kendine özgü mikroskopik görünümü vardır. ${ }^{[2]}$ İnverted ve onkositik tip, yan burun duvarından kaynaklanırken; fungiform tip tipik olarak nazal septumda yerleşim gösterir. ${ }^{[1,3]} \mathrm{Bu}$ lezyonlar benign olmakla birlikte maligniteye dönüşüm potansiyelleri (\%6-17) nede-
Schneiderian papillomas (SPs) are rare benign exophytic neoplastic proliferations originating from Schneiderian mucosa which surrounds the nasal cavity and paranasal sinuses. Histomorphologically, they are classified into three groups including inverted, fungiform, and oncocytic SPs. In contrary with inverted and oncocytic Schneiderian variants, fungiform SPs occur in younger age and typically originate from the nasal septum and are not related with malignancy. Complete surgical excision is the best treatment modality for fungiform SPs. A 68-year-old female patient was admitted to our clinic with unilateral nasal obstruction and xerostomia. The endoscopic examination revealed a polipoid mass obstructing the left nasal airway. Histopathological examination of the mass, which was excised totally, revealed as SP fungiform type. The clinical and histopathological characteristics of fungiform SPs were presented in the light of related literature, as it is rarer in elder people unlike other Schneiderian variants.

Key Words: Nasal cavity; neoplasms; papilloma; paranasal sinuses.

niyle önemlidir. ${ }^{[1,3]}$ İnverted papillomlarda malignite potansiyeli daha fazla olup, fungiform SP'ler ise maligniteye dönüşüm riski taşımaz. ${ }^{[4]}$ Schneiderian papillomların yaklaşık \%19-50'sini oluşturan fungiform papillom, diğer iki tipe göre daha genç yaşlarda görülür. ${ }^{[1]}$ Tipik olarak nazal septumdan kaynaklanır; yan burun duvarı ve paranazal sinüslerde nadir görülür. ${ }^{[1,3]}$ Nüks ihtimali diğer SP tiplerine göre daha az olan fungiform SP'lerde en uygun tedavi yöntemi geniş lokal eksizyon olup prognoz da oldukça iyidir. ${ }^{[1,4]}$ 


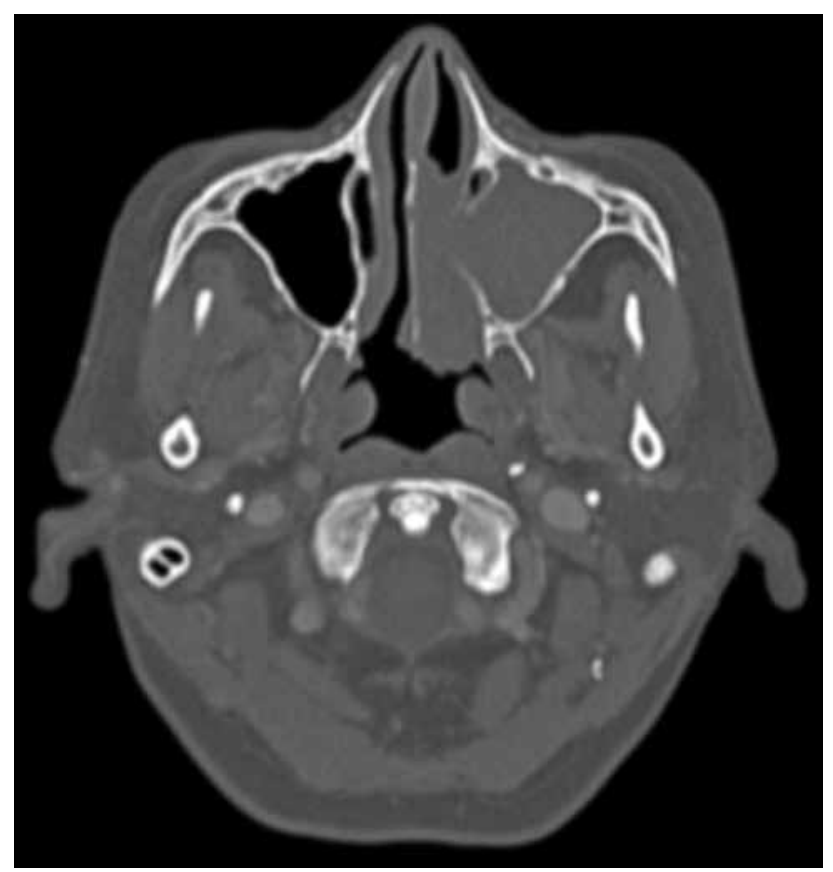

Şekil 1. Hastanın ameliyat öncesi paranazal sinüs bilgisayarlı tomografi görüntüsü.

\section{OLGU SUNUMU}

Altmış sekiz yaşında kadın hasta, bir yıldır olan burun tıkanıklığı, ağız kuruluğu yakınması ile polikliniğimize başvurdu. Ön rinoskopik muayenesinde sol burun boşluğunu tamamen dolduran polipoid kitle izlendi. Rutin kan tahlilleri normal olan hastanın bilinen hipertansiyonu, konjestif kalp hastalığ 1 ve bir y1l önce gecirilmiş baypas ameliyatı öyküsü vardı. Sigara alışkanlığı ve alerji semptomları bulunmayan hastanın paranazal sinüs bilgisayarlı tomografisinde (BT) sol maksiller sinüste sinüsü tama yakın oblitere ederek burun boşluğunun sol yarımına uzanım gösteren, sinırları orta ve alt konkalardan ayırt edilemeyen antrokoanal polip ile uyumlu olduğu düşünülen yumuşak doku izlendi (Şekil 1).

Genel anestezi altında endoskopik cerrahi yöntemiyle papillomatöz kitleler total eksize edildi, sol maksiller sinüs medial duvarı da doku örneklerine dahil edildi. Kitlenin histopatolojik incelemesinde; ekzofitik lezyonun, stromada çok sayıda damarlanma ve fibrovasküler kor yapıları ile karakterize papilla yapıları içerdiği (Şekil 2a, b); hücrelerde nükleer pleomorfizm ve belirgin mitotik aktivite izlenmediği gösterildi ve patoloji sonucu fungiform tip Schneiderian papillom olarak bildirildi. Kliniğimizde takibe alınan hastanın dört yıllık takiplerinde nüks izlenmedi (Şekil 3).

\section{TARTIŞMA}

Schneiderian papillomların üç tipi vardır; en sık görülen tipi inverted tip olup \%47-73 oranında görülürken; fungiform tip \%19-50, onkositik tip ise \%3-8 oranında görülür. ${ }^{[1]}$ Fungiform SP'ler gençlerde (özellikle 20-40 yaşlarda) ve erkeklerde daha sık görülmesine rağmen olgumuz 68 yaşında bir bayan hasta idi. Schneiderian papillomlarda en sık görülen semptom burun tıkanıklığ1 olmakla birlikte hasta burun kanaması, akıntı, baş ağrısı, koku alamama gibi yakınmalarla gelebilir. ${ }^{[3]}$

İnverted ve onkositik tip siklıkla yan burun duvarında, fungiform tip ise klasik olarak nazal septum$\mathrm{da}$ yerleşim gösterir. ${ }^{[1,3]}$ Bizim olgumuzda ise tümör yan burun duvarında ve maksiller sinüsten kaynaklanmakta idi. Schneiderian papillomlu hastaların yaklaşık

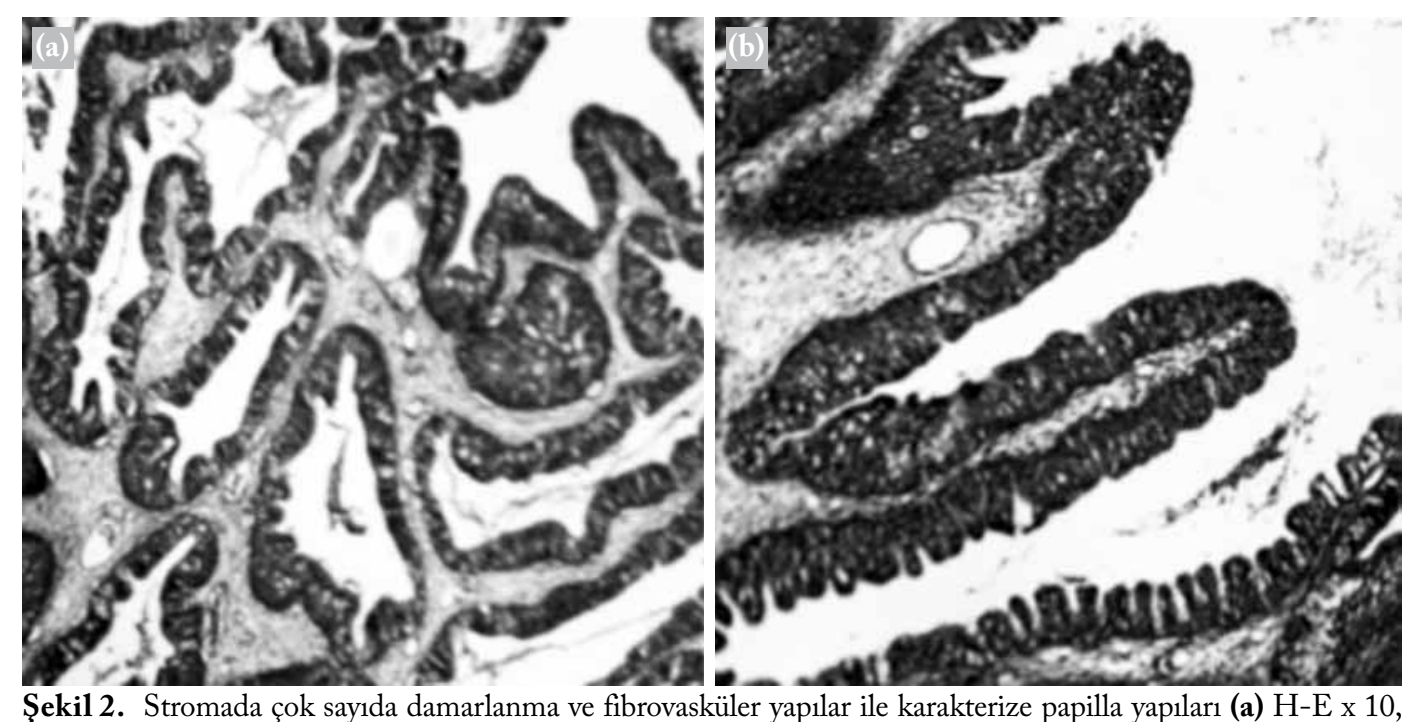

(b) $\mathrm{H}-\mathrm{E} \times 40$. 


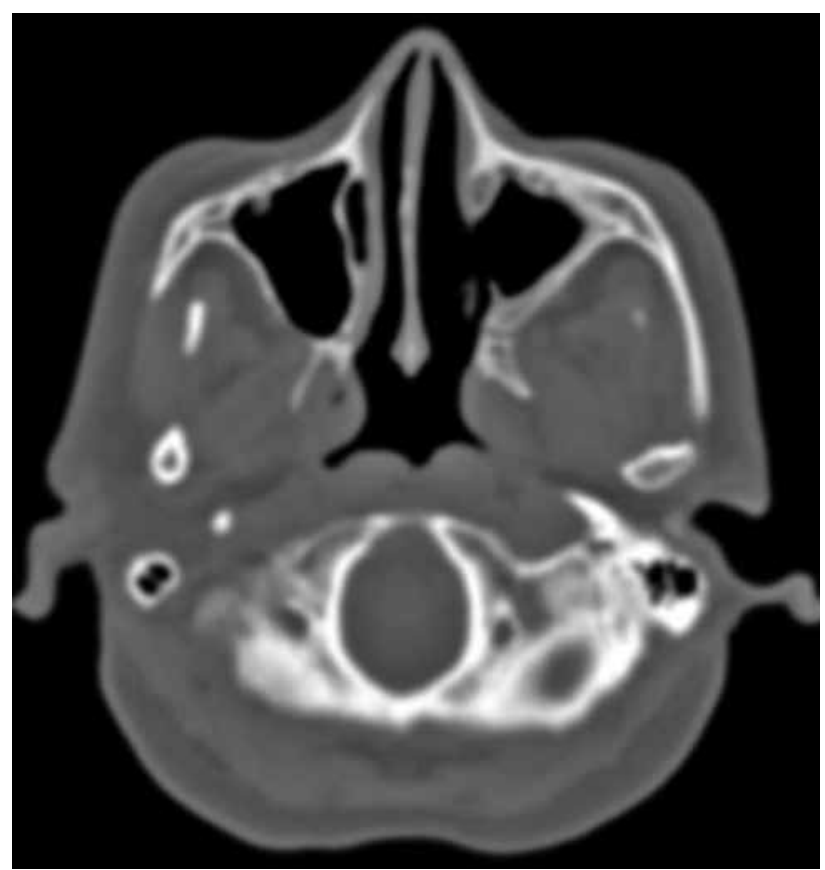

Şekil 3. Ameliyat sonrası 3. yılda kontrol paranazal sinüs bilgisayarlı tomografi görüntüsü.

\%70'inde BT'de kemik erozyonu saptandığı bilinmektedir. ${ }^{[3]}$ Hastamızda da sol maksiller sinüs iç yan duvarının erode olduğu görüldü.

Fungiform SP'ler, papiller skuamöz hücreli karsinom ile karışabilir. ${ }^{[1]}$ Nükleer pleomorfizm, stromal invazyon ve belirgin mitotik aktivitenin olmaması papillom tan1sını destekleyen önemli bulgulardır. ${ }^{[1]}$ Hücrelerde mitoz çok nadir görülse de atipik mitoz hiçbir zaman görülmez. Enfeksiyon eşlik etmediği sürece stromada enflamatuvar hücre görülme oranı çok düşüktür. Yüzey epiteli yass1, transizyonel (intermediate) veya silyalı kolumnar epitel olabilir. Mukus salgilayan Goblet hücreleri yaygin olarak izlenir. ${ }^{[3]}$ Yaygın yüzey keratinizasyonunun bulunmaması, mukus salgılayan hücreler içermesi, silyalı veya transizyonel epitel varlığı; fungiform papillomların nazal vestibülde görülen keratinize cilt papillomlarından ayrımının yapılmasında önemlidir. Fungiform papillomlar ekzofitik büyüme özelliği gösterirken inverted papillomlarda epitel yüzeyinden stroma altına uzanan invajinasyon alanları ile karakterize endofitik büyüme paterni vard $1 r^{[3]}$

Son yıllarda fungiform SP'lerin insan papilloma virüs (özellikle tip 6 ve 11) ile ilişkili olduğunu gösteren çalışmaların sayısı giderek artmaktadır. İnverted ve onkositik tip SP'lerde maligniteye dönüşüm riski ve nüks olasıllğ 1 nedeniyle geniş cerrahi eksizyon ve nüks açısından hastaların uzun dönem hatta ömür boyu klinik takibi gerekmektedir. ${ }^{[3,5]}$ Fungiform SP'lerde maligniteye dönüşüm görülmemesi ve nüks olasılığının düşük olması nedeniyle geniş lokal eksizyon yeterli olup, prognoz da oldukça iyidir. $^{[1,4]}$ Olgumuzda endoskopik cerrahi yöntemle kitleler total olarak eksize edilerek, sol maksiler sinüs iç yan duvarı rezeke edildi. Dört yıllık takip süresince nüks görülmedi.

\section{Çıkar çakışması beyanı}

Yazarlar bu yazının hazırlanması ve yayınlanması aşamasında herhangi bir çıkar çakışması olmadığını beyan etmişlerdir.

\section{Finansman}

Yazarlar bu yazının araştırma ve yazarlık sürecinde herhangi bir finansal destek almadıklarını beyan etmişlerdir.

\section{KAYNAKLAR}

1. Çallı Ç, Öncel S, Pınar E, Bolat F, Çallı A. Nasal fungiform Schneiderian papilloma: a case report. Turk Arch Otolaryngol 2004;42:225-8.

2. İnci E, Yılmaz S, Güvenç MG, Mamak A, Cansız H, Yağız C. Sinonasal papillomas: histologic types and our treatment results. Turk Arch Otolaryngol 2005;43:13-7.

3. Çukurova İ, Özkul MD, Ciğer E, Arslan İB, Koçdor P. Schneiderian papilloma originating from sphenoid sinüs. Turk Arch Otolaryngol 2006;44:99-102.

4. Steiger JD, Chiu AG, Whitney-Miller C. A sinonasal inverted papilloma of mixed histology: implications for management of all sinonasal papillomas. Ear Nose Throat J 2007;86:752-3.

5. Yaman H, Öztürk K, Ünaldı D, Toy H, Arbağ H, Özer B. Three cases of inverted papilloma. Genel Tip Derg 2006;16:133-5. 